\title{
Faculty Roundtable Discussion
}

\author{
Moderator: KEVIN ROBERT FROST ${ }^{1}$
}

\author{
Participants: PAUL BELLMAN, M.D., ${ }^{2}$ CALVIN J. COHEN, M.D., ${ }^{3}$ \\ JUDITH CURRIER, M.D., ${ }^{4}$ JAY DOBKIN, M.D. ${ }^{5}$ WAFAA EL-SADR, M.D., ${ }^{6}$ \\ MARK HOLODNIY, M.D., 7 AMY LEONARD, ${ }^{8}$ SAMUEL MERRICK, M.D., ${ }^{9}$ \\ LAURA PINSKY, C.S.W. ${ }^{10}{ }^{10}$ DAVID S. RUBIN, M.D., ${ }^{11}$ MICHAEL SAAG, M.D., ${ }^{12}$ \\ and ANITA VAUGHN, M.D. ${ }^{13}$
}

\section{SELECTING INITIAL REGIMENS}

MR. FROST (MODERATOR): I want to ask Dr. Saag, the question that I think is probably one of the most frequently asked. What do you start treatment with? Suppose a new patient, with no retroviral history, comes to you with a CD4 count between 400 and 500 and a viral load of 10,000 to 15,000 copies.

DR. SAAG: There is more to consider in initial therapies than just retroviral load and CD4 count. It is also about who are they as a person, how motivated are they, and are they ready to start therapy?

MR. FROST (MODERATOR): Let's say, as a patient, I am ready to start. I am ready to go. DR. SAAG: Alright. Then in talking to you, I would find out whether you want to be hy- peraggressive or whether you want to be more conservative in treatment approach.

MR. FROST (MODERATOR): "Gosh, I do now know, Doc. You tell me."

DR. SAAG: In that case, with a CD4 count of 400 and a viral load of 15,000 , I would personally recommend that you take $\mathrm{d} 4 \mathrm{~T}$ and $\mathrm{ddI}$ to start-with the notion that we are not going to be reducing too many options; we have a lot of treatment possibilities to go. I think it is very likely we will get you to an undetectable viral load, and you can stay there for 5 years.

What is bothersome to me is a self-flagellation that many of us are engaged in who have been in this for 10 years or longer, such as, "Oh, we really blew it. We used AZT monotherapy, and we used ddI monotherapy." Well, that is what we had at the time. And those drugs can-

\footnotetext{
${ }^{1}$ Director, Clinical Research and Information, American Foundation for AIDS Research (AmFAR).

${ }^{2}$ St. Vincent's Hospital, New York, New York.

${ }^{3}$ Research Director, Community Research Initiative of New England, Brookline, MA.

${ }^{4}$ Assistant Professor of Clinical Medicine, University of Southern California, Los Angeles, CA.

${ }^{5}$ Associate Professor of Clinical Medicine, Department of Medicine, Columbia Presbyterian, New York, New York. ${ }^{6}$ Director, Division of Infectious Diseases, Harlem Hospital Center, New York, New York.

${ }^{7}$ Assistant Professor, Stanford University, Director, AIDS Research Center, Palo Alto VA Medical System.

${ }^{8}$ Assistant Director of Education, AIDS Foundation Houston.

${ }^{9}$ Assistant Professor of Medicine, Associate Director, Center for Special Studies, The New York Hospital-Cornell University MedicaI College, New York, New York.

${ }^{10}$ Columbia University, New York, New York.

${ }^{11}$ Clinical Instructor of Medicine, Cornell University Medical College, Director AIDS Center, New York Hospital, Queens, New York.

${ }^{12}$ Associate Professor of Medicine, Director, AIDS Outpatient Clinic, University of Alabama, Birmingham.

${ }^{13}$ Newark Community Health Center, New Jersey.
} 
not carry a person through an entire decade. But I personally would give that regimen to keep options open. In my experience, it works $80 \%$ to $90 \%$ of the time for at least 3 to 5 years.

DR. CURRIER: I think I would also want to involve the patient in the process of what therapies we are going to begin with; that is, we are going to make that decision together. And I would try to give the patient as much information as possible about the short-term activity of our choice and the probability of reducing the viral load down to a level where we think it would stay. I would tell you that if we treated you with AZT, ddI and, nevirapine, in a year, there is about a $50 \%$ to $60 \%$ chance that your viral load would make it to an undetectble level, and that if it did, it may stay there for a long time.

We would have to guess about the efficacy of ddI, d4T, and nevirapine. There are no data on that published in a study. I would tell you that with the protease inhibitor combination regimen, we probably have a better chance of achieving an undetectable viral level. But I could not tell you how long you would remain there, or what we would do that would be successful afterward.

I think with the CD4 in the range that you mention and a viral load of 10 to 15,000 -an area where I would still feel comfortable recommending a nonprotease regimen, although I would not use 3TC-I would make a strong argument for nevirapine with AZT and ddI. But I also say that there are very good data to support that you may have a long term effect with a protease inhibitor.

MR. FROST (MODERATOR): Why are you holding back using 3TC?

DR. CURRIER: I think that the possibility of failure, that is, if $I$ just went with the AZT-3TC-nevirapine and you develop resistance to that regimen, it may make the other proteases less active in the future. Holding back the 3TC may provide the long-term durability we have seen in the Merck 035 and other studies. So I would save 3TC for a protease containing regimen.

DR. COHEN: What is nice about this patient is that he is likely to respond to every single regimen we have talked about and then some.
I personally think that it is possible to use either all proteases first or all nucleosides first, and successfully switch to the other if needed, because of the lack of cross-resistance. We have done some work with hydroxyurea, which seems to improve the percentage suppression with ddI-based regimens, is relatively easy to use, and is well tolerated. At least in patients whose CD4s were above 300, we saw increases in CD4 counts in our study.

MR. FROST (MODERATOR): Dr. Merrick, what are your thoughts concerning this hypothetical patient?

DR. MERRICK: Rather than just starting something at the first visit, I want to mainly gauge the level of commitment that you, as the patient, have.

MR. FROST (MODERATOR): I am ready to start treatment.

DR. MERRICK: And what about your level of understanding of toxicities?

MR. FROST (MODERATOR): I am clueless.

DR. MERRICK: Note, that is the first time he (Mr. Frost) has ever said that. The patient needs to understand, especially early on, the level of toxicities of all the drugs, including a d4T-ddI regimen, which is generally well tolerated. But my own thinking is that durability really is the key. What I say to patients is that I would like to start a regimen that we are never going to have to change.

If your definition of success is viral eradication, I think that all regimens are perhaps doomed to failure because I think eradication has proven to be elusive. But if we lower the bar just a little bit and just say that we want to start a regimen that will be durable for the foreseeable future, in terms of years, then I would favor starting with a triple-therapy regimen, including a protease inhibitor. Again, one has to factor in adherence. And that involves a lot of time talking to a patient even before you think about starting a regimen. But, of course, in this case it is not an emergency setting.

MR. FROST (MODERATOR): Assuming those things are equal, I understand you to be saying that a protease is something you are leaning toward more in the initial regimen. Yes?

Ms. Leonard, I am going to change the ques- 
tion for you because I am hoping you can give us an idea of the clients that you counsel in Houston and about the education you provide for them. What types of regimens are clients talking about, and what is the AIDS Foundation of Houston talking about in terms of initial therapy for patients when they come to see you?

MS. LEONARD: I am more for starting treatment, in the case we are discussing, with a dual therapy regimen without proteases, because the clients that we see have trouble accessing the protease inhibitors. I explain to them what the ddI pill looks like, what it means when they take it, that is, not eating before and not eating after. You are talking about people, if they are employed or if they are not employed, and how that is going to affect their life-style. It is a very nasty pill to take, and they need to know that before they go to the pharmacy to pick up this huge horse pill. All of this needs to be explained along with the question, "Are you ready to commit?" They may be ready to commit, and so they take their prescription with their life-style-and everything is a little bit harder. But I am definitely for starting off in this particular case with dual therapy.

DR. DOBKIN: I agree with most of what has been said. Let me just add another point. I think an option that has not really been mentioned is the option of waiting. I think it is clear to most of us that eradication or cure is in the distant future. But much better regimens are around the corner. I think we have to remember that the possibility of effective treatment may not always occur simultaneously with a tolerable and easily accessible treatment.

Those of us who are old enough to remember antihypertensive therapy 25 years ago, knew that you could control hypertension. But most patients could not tolerate the regimen; therefore, most patients were not in control of their blood pressure. I think the possibility, in the case you present, of waiting-not using up any of your nucleoside options-but instead applying careful observation, and then in 6 months or a year, when an easy twice daily regimen is available or even a once daily regimen, applying those at that time-this might be the best way to go with a lot of patients. I have come to increasingly feel that we are rushing many patients into therapy. I have seen series of patients who have exhausted all the drugs in the armamentarium within a year due to haphazard prescribing.

DR. EL-SADR: The issue of waiting versus initiating has not been looked at, but it might be a viable option for anyone, not just people with chaotic life-styles. And what worries me even more about these guidelines is that if you use a regimen that is not in those guidelines, it might appear unethical or as inadequate care. I feel sometimes that these guidelines, although they are well-meaning in many ways, often close the doors of potential research. Where are we using plain gut-sense and extrapolating from clinical experience? I mean, I honestly do not know.

MR. FROST (MODERATOR): I think your insights are appropriate and good. And I think, especially in reference to the guidelines, which I want to come back to, there are some interesting aspects to consider. But, hypothetically, I am your patient, and I am telling you that I am ready to go forward with treatment. I purposefully painted a picture of a patient who is sort of in the gray area of the guidelines, someone who may be on the edge. However, I am telling you "You know, I am probably ready to start. I think it is time. I have had enough friends who have done very well on these proteases. I think it is time for me to start." Where do we begin?

DR. EL-SADR: You say you are ready to start, but you also mentioned that you were clueless, and that is often the case with patients. They feel they are ready, but they really do not know what they are ready for. I am perfectly comfortable with a two-drug regimen because I am not convinced yet that, in the long run, based on what we know today, based on a whole different approach to suppression versus eradication, and all of the patients discussed, that we know the best option.

DR. HOLODNIY: I believe that I am another person that would hold back the use of protease inhibitors in a case such as this where the patient has a high CD4 count and a relatively low viral load. But I have another reason as to why I would do that.

I also look at the level of virologic risk. I be- 
lieve the patient that you are asking about now is in the minimal to moderate range of virologic risk, that is, if we are to believe any of the prognostic data. And so I believe there is a potential argument for waiting, given the existing CD4 count and level of immune function in that particular patient. There is also an argument for very aggressive therapy as well as triple or quadruple therapy to bring the load level down to less than 20 copies and maintain it. In a drugnaive patient, the opportunity to do that and sustain that level for at least 2 years or longer is clearly there. So I think that is part of it.

Another issue is what do you come to the table with, not only in terms of the psychosocial aspect, but in terms of what other concomitant illnesses and toxicities already exist, and do not include the antivirals? Do you have a significant anemia? Do you have pancreatitis, hepatitis? These are common in the Veterans Administration patients that I treat. Are these issues that are going to enter into the mix? So, those possibilities have to be factored in as well. I do not think there is on "regimen du jour" that everybody is going to be able to take.

MR. FROST (MODERATOR): Yes, I didn't expect that we would find one regimen from this. I only wanted to find your regimen.

DR. HOLODNIY: I cannot tell you that. There are people that I have started on d4T-ddI. There are people that I have started on AZT-3TC. There are some people that have started on two nucleosides and an NNRTI or a protease inhibitor, or just two protease inhibitors.

MR. FROST (MODERATOR): But you are giving me some sense of what you are comfortable with. And it sounds like it is a twodrug regimen that you are perfectly comfortable with, despite it being ...

DR. MARK HOLODNIY: I have also been comfortable waiting.

DR. BELLMAN: I will put a slightly different spin on this in two ways. First, I would try to get the patient excited about the possibility of effective treatment. Clearly, you already have some excitement about it because you mentioned that friends are under treatment and they are doing well. You do not seem to feel you really need to know that much about treatment in order to plunge right into it. I also think that one consideration is that after 2 or 3 months, if I can tell you that your viral load is undetectable, that everything is going great, and there are no toxicities from the drugs, that accounting is going to build your enthusiasm, and potentially your compliance would continue.

And also, you may be started on the path of what we are hoping is viral eradication, or at least enough viral suppression that, at some point, perhaps therapy could be discontinued, and then you could be monitored, and if necessary, return to therapy.

Since the drug regimens that we have now, in relation to the amount of antiviral potency that you require, are so good that it would be very reasonable just to go with what is currently the "gold standard" in therapy: AZT, 3TC, and indinavir (Crixian). This would be assuming that you were very clear regarding the issues about compliance at every level. I would certainly want to monitor you very closely with respect to that issue. I would add that the regimen with saquinavir has no place in the guidelines, and I think it is an important question to ask, in terms of ourselves, why that regimen is actually in the guidelines at this particular point.

MR. FROST (MODERATOR): Does anybody disagree with that? Would anybody take issue with the position regarding the guidelines that the two nucleosides and saquinavir should not be there, at least the old formulation?

DR. BELLMAN: More harm can be done because of protease cross-resistance and because of what we have seen with people who have switched from saquinavir and are unsuccessful when they switch. As a result, I think it is better to say, at the present time, that because of cross-resistance, more harm can be done using saquinavir in an undertreatment form.

MR. FROST (MODERATOR): Dr. Vaughn, what are your thoughts in terms of a first regimen?

DR. VAUGHN: For the population that I serve in Newark, people usually come with a laundry list of what they will and will not tolerate. Up until very recently, if it was AZT, forget it. They did not want to hear and they were not going to take it. What I do with clients is basically an inventory of life-style, considering 
meals, whether the patient works or whether they do not work, how structured their life is, and then also how compulsive they might be. Because I think a better measure of adherence is (1) believing that medication is going to work and (2) compulsion. A very compulsive person tends to take his medicine. Those of us who are not so compulsive do not.

I would probably be a little more aggressive. Up until the AIDS meeting in Vancouver 2 years ago, clearly about $35 \%$ of my patients refused to take any medications-either never started or stopped. And the Concord just confirmed what they felt. But post-Vancouverwhen Magic Johnson was on the cocktail-people began saying, "I want whatever he is on. Give me some of that."

Also, the assumption that if a person is homeless or cannot read then he or she is not informed about this disease is not true. I have seen that in my community because we have taken special efforts to educate the population. We have focus groups, support groups, and community forums on a very regular basis. A lot of times, my patients educate me about therapies. I have discussions with them, and then I tailor them to what they can tolerate. I use a lot more ddI-d4T now than I did in the past because early on I had a lot of patients who had a history of pancreatitis. Why? Because a lot of folks like Colt 45 and all that other good stuff. Then of course, some medications have a better rap than others since they have seen and been with their buddies. And so I tend to use combinations that do not contain AZT, and also to use Crixian in the cocktail.

We want to hopefully help patients work with family members, the community, peer educators, as well as patients who have been through these decisions in a buddy system. By the time patients leave my office, they have a rigorous schedule that I have worked out with them. Or perhaps it is not the initial encounter; I have worked with people for several sessions before I am sure that they are ready, that they are committed to taking the medication. Then we work out a schedule about what they are going to do. For example, with the type of patient you suggested, if they are going to take ddI, they are going to wake up and take this medication first. After that, they are going to wait and take the pills afterward. I explain the meal they are going to eat, etc. Then I turn the patient over to a nurse, a case manager, who has a further discussion with them. A buddy system is established with an experienced patient with whom they exchange telephone numbers. The experienced person telephones every day at different times to reinforce the need to take the medicine and keep other commitments. We will also discuss what they might have to do to overcome some of the side effects.

I am on call all the time as well as the nurses. So patients and family members can call if they have questions that they do not understand. If we find out through these conversations that the patient is not taking the medications, we can intervene early instead of later. There are frequent support group and forum discussions which allow questions that we may not think are really important, but they can be brought up and answered right away.

MR. FROST (MODERATOR): It sounds to me like there is a strong emphasis on the individualization of therapy for that patient in your clinic. Dr. Rubin, how would you address treatment, as I described myself hypothetically as a new patient with no retriviral history, a CD4 count between 400 and 500 , and a viral load of 10,000 to $15,000 ?$

DR. RUBIN: The way I usually handle the situation in your case would be to try and assess the motivation level and the education level of the individual. If I feel that the person can handle a protease inhibitor, and he or she is ready, I would try to use triple therapy with a protease inhibitor. I am hooked on triple therapy. I know we are hearing from the panel that double therapy at an earlier stage may actually be the more prudent thing to do, but I am still with the old school. I think that may results are so good, in terms of the viral load changes in the patients that I have treated, that I will not change approaches unless I see some compelling evidence to do so.

I use nevirapine with nucleosides as an alternative regimen for patients whom I do not feel would really be able to comply with the protease inhibitors, in patients who are naive, and in patients who are earlier on in the course of their disease. My results have been equiva- 
lent to using a protease inhibitor. With patients who are symptomatic or more advanced, I am more aggressive about encouraging the use of the protease inhibitor. I have found that there has been very little difference; except in heavily pretreated patients, between responses in some of my more advanced patients and some of my earlier patients in terms of CD4 changes. So I tend to be very aggressive, but I do gauge the issue of compliance, and I do try to make that a major point of discussion as well as subsequent discussions in terms of gauging how adherent the patients have been with the regimens.

\section{GUIDELINE CONTROVERSIES}

DR. PINSKY: I wonder if I could ask a question from the point of view of your patient. Regarding the guidelines, if I were to come in and say, "I am almost clueless, but I read about treatment issues in these guidelines that were put together by all these fabulous experts, and they do not seem to agree with what you are telling me. What has changed, or why do you disagree with them? Could you explain that to me in a language that someone who has only taken a year of biology could understand?"

MR. FROST (MODERATOR): I think that is a fair question. And I am going to add an additional spin. I heard a few people on the panel say they would use protease inhibitors aggressively, and then I heard other people say they might spare protease inhibitors. But I heard very different reasons for why people might spare protease inhibitors, or why they might use dual nucleoside therapy. And I guess it is a fair question, what has changed in terms of these guidelines? Is it that the guidelines do not reflect state-of-the-art treatment, or are the guidelines, as we often say here, appealing to the lowest common denominator? What is going on here?

DR. SAAG: Well, having participated in the development of some of the guidelines, I will just make a couple of statements. Number one, let's think about who the guidelines are for. They certainly are not for most of the people in this audience, nor for the people on this panel. Health-care providers that see a lot of patients do not need the guidelines as they keep up with what is changing. They see over 100 patients. They do not need guidelines to tell them what to do. The guidelines might make them feel guilty about what they are doing, but they are not going to tell them what to do.

For the people that only see a patient here or there, the guidelines may be harmful because they may encourage them to use therapies about which they have little or no idea of what they are doing. It would be like me treating a lymphoma or leukemic patient. It have no business doing that. I think if somebody only sees a patient now and then, they should not be treating at all and should not be using the guidelines. Unless there is no option in the community, which certainly is not the case in the New York area, those people ought to be referring to somebody who does treat patients.

So the guidelines basically are political. They are there to help third-party payers do what they should not be doing, in my opinion. That is why, in my view, even though I am one of the persons that developed the recommendations, I just recommended something that the guidelines said is generally not recommended. The reason I acquiesced was to say, what difference does it make? If I wanted to choose all three agents, I do not want a third-party payer saying, "Well, the guidelines say you are not supposed to do that in this setting." So, I think having them err on the side of overaggressive therapy, in my opinion, was appropriate. That is basically wanting to have a reality check there.

MR. FROST (MODERATOR): Is that something you might say to a patient?

DR. SAAG: Absolutely. You bet.

MR. FROST (MODERATOR): These are political guidelines? They do not really tell me how to ...

DR. SAAG: Well, I do not know if I would go into all that much detail. To answer your question, I would speak in biologic terms. That is not so hard to understand. We use the terms "a billion to ten billion viruses produced a day." That gets people's attention, or you can translate more figures to " 485 million virions an hour." That is a pretty heavy viral load. That is easy to understand.

If I had to summarize, when most patients 
come in, this disease is very mysterious to them. They do not understand how they can feel well and be told all these bad gloom and doom things that are going to happen to them in the future. They do not understand why it is not happening now, or why it is not happening tomorrow, exactly tomorrow. When I start to explain the biology, you can often watch the light go on. Then when I start talking about therapy, again, I make a clear distinction between clinical benefit and prevention of resistance. That is how I couch the discussion, that what we are really talking about is the importance of viral load, that it is a measure of how effective these therapies are before you might get sick from the disease. I explain that if we focus on that as our yardstick-as our virometer, if you will-then we can know in advance when to switch therapy. They need to understand this concept as a guiding principle as opposed to always looking for another in clinical trials that are waiting for people to be on their way to the grave.

\section{ARE ALL THERAPIES DOOMED TO FAILURE?}

MR. FROST (MODERATOR): Fair enough, I think. You know, this very bright doctor that I know tells me that all of these therapies are doomed to failure. I am wondering-does the panel agree? Because that is really bad news to me. Are all these therapies doomed to failure?

CAL COHEN: I think what Dr. Saag said is that we do not know if some of these regimens we have talked about might last for as long as this person is alive. I think what is accurate is that it is entirely possible that some of these regimens we have all used, and like using, may work for the life of the patient. We certainly all have patients who are successful beyond our wildest dreams from 2 years ago; they went from $42 \mathrm{~T}$-cells to $442 \mathrm{~T}$-cells. They are as healthy as they want to be, have managed to take the pills on schedule, and are doing great. We are now 2 and 3 years into this situation. If the first 2 and 3 years are any prediction of the next 30 , then it is possible that some of these regimens will last for life. I think that's obviously what we're looking for.
I think what Dr. Saag says is not that in each person the regimens are doomed to failure. It is that in a subset of people that we give these agents to in a population that we treat, this approach does not seem to be holding. And since we do not yet know how to predict who is going to be the success and who is not, then it makes us a little gun shy. If I could predict in whom this triple therapy would be successful for the rest of their lives, I would give it to only them and not to other persons.

But we are still learning how to do this. If you get gun shy, you are likely to say, "Well, I guess I will back off with everybody." I think the challenge for 1998 is in predicting failure, as opposed to expecting it. In predicting it, what are the things that allow us to say, "You know what? This regimen is working. It will continue to work. And all these tests will tell me that confidently." I do not think we have those tests yet.

I think what we need is something between Mark Holodniy's talk on therapeutic drug monitoring and perhaps the "Star Trek moments" in which you can just kind of go "Whew!" and tell that the regimen is working.

MR. FROST (MODERATOR): Well, Dr. Saag, are you saying, that all these therapies are doomed to failure or ....?

DR. SAAG: We should assume that they are doomed when we think that that should be a driving force of our thought process so that we are not just blissfully waltzing down the "Yellow Brick Road," running toward Oz. We should be thinking, "What if? Be prepared." And hopefully they will not fail. But what if they do?

In the case that you presented, I sort of backed into a default mode with $\mathrm{d} 4 \mathrm{~T}$-ddI. If you made the viral load higher, I would have been more aggressive and used triple-drug therapy or even quadruple-drug therapy with a whole different focus for that individual, even if the CD4 count were lower. I think that it all depends. I am just saying you should be prepared for failure.

MR. FROST (MODERATOR): Yes, I hear that. And I understand that this is an intellectual process, to a certain extent, that you are using as a tool because you are thinking ahead. How much of that process do you share with 
patients? Would you say to a patient, "This is what I'm doing for you today, but ..."

DR. MICHAEL SAAG: You bet. When I write down that plan, I am talking to the patient about it. "This is what we are going to start you on today. This is what we want your viral load to be in 8 to 12 weeks. This is what we are going to do if and when this regimen no longer works. And this is likely what we are going to go to. What do you think of that?" So that we're on the same page together literally.

And that is critical to starting regimens because when you lay it out for patients, they may say, "No, no, no. You know, I'd rather not do this d4T-ddI thing. Let's move into more aggressive therapy." Great! Let's do it.

By bringing the patient into the process, you not only improve adherence, they are more engaged because they're part of the team now.

MR. FROST (MODERATOR): Sure. You're looking at these viruses in the test tube. And you're looking at them even in patients who have really low viral loads. Are these regimens going to fail these patients? Are we going to find resistance?

DR. HOLODNIY: As I alluded to in my discussion, in some patients we do, and in some we don't. And to go one step further about initiation, I have some patients in the clinic who are on AZT monotherapy, or they're on d4T monotherapy. Their CD4 counts are 300, 420 with Viral loads of 1100,600 , respectively. They have been on those monotherapies for 5 years. We have the same discussion every 4 months. I say, "You know, this is not good. It's against the guidelines."

And they say, "Well, but, what has changed if anything over the last 36 months?"

And I say, "Nothing."

And they say, "Well, why should I add anything?"

And I say, "Well, the national opinion leaders suggest that you need to be on more."

And they say, "I don't want to be on more. I'm comfortable where I'm at. I'm trending what's going on. I'm tracking it with you. And I don't need to be anything."
Now, when you fish some of those viruses out of people, believe it or not, it is a crapshoot. Some of them have, believe it or not, resistant virus. Yet, they have very low viral loads, and their T-cell counts haven't changed. Some of them have wild-type virus, or they have mixtures. I have this sense of urgency that I need to add or change agents. But if I look at the bigger picture over 5 years, what immunologically or virologically has changed in that person? The answer is, not much.

So in those particular people, I am not sure that information helped me. It confused me more. And I look again at what we have looked at for years and years. And that is: What is the T-cell doing over time? Then I add the dimension of viral load. The resistance testing did not help me in that regard.

However, there are clearly people in whom-and this again is not necessarily in the drug-naive patient, but in the heavily-experienced patient-some additional information can be useful. It is really in those people that I look at resistance issues and say, "Okay. The genotype is this, and that allows me to go down this pathway." Or, "The genotype is this, and I cannot go down this pathway based, at least, on the rules that we understand today."

\section{RESISTANCE TESTING}

DR. SAAG: Let me react to that just for a second because I' $m$ not sure that the genotype tells us what direction we can and cannot go in. Let me play devil's advocate for a minute.

DR. HOLODNIY: Okay.

DR. SAAG: We have Dr. Vicki Johnson at our site who does resistance testing as part of the research. Therefore, the patients receive testing free. We have her come in and we play a game where, when the data comes back, I'll say to the nurse practitioner, "Okay. Give me information, either their resistance data or their regimen. And I will predict the answer." And it is not that I am so smart. It is just that it is easy to predict.

If the nurse gives me the resistance genotype, I say, "Okay, that person has been on, in the past, this, this, and this."

And they say, "Yes, you're right," or they 
say, "Tell me what they're on, and I'll predict what resistance mutations they have."

More times than not, I am right. But it does not change what I do because, as you have said, there are mixtures of viruses. And more importantly, it is such a static determination I think it's not only a waste of money to get resistance testing as a matter of routine practice. I would argue that it is almost ethically wrong because we are paying dollars out for data that does not tell us more than what a drug history does, to play devil's advocate. Let's spend that money on the drug.

Let me just point out, I think just to be fair, since we are all talking about a radical shift in what has been the standard opinion, there are at least two arguments that are voiced to counter a lot of what is being said here.

One is what is the cost to the immune system of controlling low levels of virus, and is there some irreversible damage to having 5000 copies that we are not worried about?

And the second is cross-resistance, which we have certainly downplayed. But the question is, would $\mathrm{d} 4 \mathrm{~T}-\mathrm{ddI}$ resistance make it less likely to have subsequent success. Your first chance is your best chance because cross-resistance when a codon 151 mutation shows up might mean that, in fact, this person is going to be in a lot of trouble. Had only we treated more aggressively, maybe the regimen would have lasted for life?

So there is a kind of a two-sided coin. We may not have a vocal enough representative of that. But there are some very powerful arguments to the alternative strategy.

\section{CASE ONE}

DR. HOLODNIY: This patient had a profound response and rebounded very quickly. And that is what we would expect on saquinavir monotherapy. What we see is the rapid development of a vel-90-mutation in the protease gene, which is indicative of resistance to saquinavir. You can see that that genotype comes up essentially on par with the virologic rebound in this patient.

In this particular patient, if he were in the clinic, and you had one test to choose to monitor his therapy, you would say, "Well, viral load is what I need." He rebounded. Then I would probably say, "That was due to virologic failure-the development of resistance." I do not need to spend $\$ 600$ to convince me that I need to do something else, and he is probably resistant to this drug. So, in this particular kind of patient, genotype testing is not useful information.

It becomes a little muddier when you start getting more types of resistance mutations. And so in this particular patient, what you have is, again, monotherapy with a protease inhibitor.

There are other concomitant mutations that appear to be developing. We key in on the 63 mutation, which is a compensatory mutation. Some of these compensatory mutations such as the 63 and the 71 predate the development of the mutations that actually confer resistance to the drug.

So the 63 mutation pops up very quickly, which is then followed by an 82 , and subsequently by an 84 . The 82 is the pivotal mutation for ritonavir, 84 being a secondary mutation.

DR. SAAG: Yes, but look at a time frame there in his case. For you to pick that up in practice, you would have to be doing genotyping every 30 days, or 15 days. I mean, is that reasonable? I mean, what have you gained by that?

DR. HOLODNIY: Well, right now it is not reasonable, because we do not know what the rules of engagement are. But if we get better at this, and we actually have a good data base and a knowledge base as to what these mutations mean, we can soon know if a 63, in fact, has predictive value.

DR. SAAG: Or does it come up in every patient? ...

DR. HOLODNIY: We do not know that.

DR. SAAG: That is my point.

DR. HOLODNIY: Right. And I agree with you. We are beginning to get that information out as we look at these patients and begin to understand some of the rules.

\section{CASE TWO}

DR. HOLODNIY: The next patient is a patient in my clinic. He has been infected since 
about 1986, heavily nucleoside pretreated, and was on saquinavir when it first came out. Then the regimen was switched to indinavir. He was genotyped at this particular point after having been on two protease inhibitors. And surprising to me, he had failed on an indinavir regimen. But you can see what his viral loads are. They are in the 200,000 to 300,000 range. The only note of significance in the protease gene was a vel-90-mutation, which he had developed from saquinavir therapy. He did not have any of the other mutations that are associated with indinavir. This is a very compliant patient. Also, at this point in time, he did not have the pivotal mutation that we think goes along with nelfinavir resistance.

So this patient has his whole regimen changed. This time we went by the guidelines. And low and behold, he had no response to a nelfinavir-containing regimen. The question is why. What we have found in this patient, and at least four or five other patients, and some data that Agauron actually has, is that in patients-in the absence of a D-30 mutation, but in the presence of a v-90 mutation, they will not respond to nelfinavir.

So, there again we begin to describe new rules of what we can use next in terms of a salvage regimen. And this was very surprising to me, but not unexpected based on where that mutation is in the active site, and the possibility that the drug will not work because of that mutation.

I have five patients in the same boat-I know if I have this mutation information, with nelfinavir, that the possibility of diarrhea and the possibility of other drug interactions are real and they are not events I want to introduce into the regimen. So in this particular case, this information was useful for subsequent patients, but not for him, unfortunately.

\section{CASE THREE}

DR. HOLODNIY: This is a patient being treated at San Francisco General who had been heavily pretreated on the nucleosides, and was on ritonavir. In addition to that, he had evidence of the 82 mutation known to confer ritonavir resistance.

Interestingly, in this patient, when they changed to saquinavir, what they saw was a nice reduction in viral load. But we also saw the disappearance of the 82-A mutation, which was unexpected in this particular patient. In fact, we saw the characteristic virologic rebound on a saquinavir regimen and with it the development of a v-90 mutation.

Now, a decision needs to be made about what to do. He has viral load in the 100,000 or so range. Where can you go? And it was interesting. Again, if you scan these particular protease codons here-wild type at 30-he does not have any of the mutations that we would see with indinavir. And surprisingly, the 82 had disappeared, and we were back to the valine wild type.

Because there were no pivotal mutations known for indinavir in this particular patient, but only the saquinavir v-90 mutation, the decision was made to change him to an indinavirrelated regimen. In this patient, we had a nice virologic response that was sustained.

DR. SAAG: If you put a block on the bottom part of the slide, you have somebody who has already failed ritonavir and failed saquinavir. You do not have many options left. You are going to be doing indinavir no matter what anyway, just on the fly. And the 3TC makes no sense because the 184 mutation is still there. Clinically, without the other data, I would have moved to nelfinavir and indinavir-d4T at a minimum, with or without a non-nucleoside.

DR. HOLODNIY: Right.

DR. SAAG: I don't know for sure, but I would bet you would get a similar response.

DR. HOLODNIY: But haven't your national opinion makers and your guidelines suggested that if you are ritonavir experienced, you cannot move to indinavir?

DR. SAAG: I would not read it that way. The bottom line is those guidelines are not meant for people that are taking care of patients every day. They are meant for the third-party payers.

DR. HOLODNIY: Right. So you would have felt comfortable, after having failed on ritonavir, to go back to indinavir?

DR. SAAG; I would have had no other choice. I would have been there just because it had not been used yet. It is sort of what Dr. Cohen said earlier: "Look at the list, see what you have not used, and use it."

DR. HOLODNIY: Even though you know 
what the rules of engagement are in the relationship between those . . .

DR. SAAG: The rules of engagements are based on about as much data as we have rules of engagement based on genotype.

DR. HOLODNIY: I agree.

DR. SAAG: You fly by the seat of your pants like we have always done. And you use what you've got.

DR. HOLODNIY: Right.

DR. CURRIER: I think the other point is that this approach may have worked for this patient, but we are not sure why. I think you have to be very careful about drawing conclusions from single patients using genotype information because we are not always sure that we know all about the things we should be looking at. It may be some important secondary mutation that the person did not have, which was they were able to do okay, rather than something that they did have.

DR. HOLODNIY: Believe me. I am not a salesman to sell the test. I am trying to make some sense out of whether the test has utility. But what you said is exactly true. I mean, we are individualizing therapy. We have to individualize where this test may be useful as well. And it is not a test for all patients.

\section{INDIVIDUALIZING RESISTANCE TESTING}

MR. FROST (MODERATOR): This brings up a question then. How do we individualize this? I'm wondering how many people are using it, and when do you use it? Who do you apply this assay to? You are not a salesman, but there are salesman out there pushing this test. And there are a lot of people in the community who are saying, "I need to have this test done. I need to know what I am resistant to so I can tell what I should take?" So when do you get it done? Who do you use it on? Who's the patient?

DR. COHEN: I would like to add something to that slide. I do not think that the response that is actually shown necessarily represents a significant clinical response because the viral load is still plateauing at a detectable level. It is possible it could go down further. But given the degree of resistance that has already oc- curred, and of course, almost certain 3TC resistance, etc., I would guess that that regimen will fail very quickly and independent of the issue of whether or not the genotypic test was helpful in terms of choosing it.

I think that, regarding salvage therapies, that genotypic testing is fairly limited in its utility. Maybe the only way that we can go is just based upon the data that accumulate with respect to what salvage regimens work, and how many of what percentage of people with respect to previous regimens they have been applied to. And that's a regimen that I just think has almost no chance.

MR. FROST (MODERATOR): Dr. El-Sadr?

DR. EL-SADR: Yes, I think this is a good example of how technology sometimes runs amok-ahead of our ability to use the technology. I am deluged with all the companies that are doing these tests. Medicaid in New York State is apparently covering these assays at this point without us being able to interpret the results.

And the key issue is what is the clinical significance? I am concerned to because I also wear a research hat. When you try to do a study how to determine the clinical significance of all these assays, with providers and patients who already think they know the clinical significance, it becomes impossible to do some of these studies. So we are stuck because they think the technology is going ahead of the knowledge in interpreting the results of these assays.

DR. COHEN: My personal response, by the way, when these salesmen come in is, "Show me the study that tells me that this test actually will help over and above my own guesswork, because I would be happy to order it once you show me that study." And since none of them have such a study, then all I can tell them is that I am still waiting. I also say if you would like to do some research to prove your test is worth the dollars, I would be happy to help you. But that is your money. That is not my money. Then you will get my money because you have proven your point.

DR. SAAG: But it is your money. I'll be very controversial. I come from a state where we have 100-plus people on a waiting list who cannot get protease inhibitors because our ADAP funding is exhausted. To receive Medicaid in 
Alabama, you must earn less than $\$ 500$ a month and have a net worth of less than $\$ 2,000$.

So to hear about a state that is paying out of their Medicaid budget for testing, when we cannot get access to drugs is disturbing. It is our money. And it is criminal in my opinion.

DR. HOLODNIY: I do not know if I would say "criminal." But I totally agree that it is irresponsible. And I don't think the studies are there.

DR. SAAG: I mean, legally criminal.

DR. COHEN: As you mentioned yourself, they are very reticent to even give us good data about the reproducibility of the test. And we just have absolutely no hard data that these tests are useful. I wasn't aware that Medicaid is paying for them. I am shocked. Someone got a genotype recently on a newly diagnosed patient they had, but have not started on therapy. Really what it served to do was make them more scared, more confused. "You know, we may have some $\mathrm{d} 4 \mathrm{~T}$ resistance. Maybe a 41 and some AZT resistance-maybe."

So now he is saying, "Well, what I'd really like to take are these three drugs because that fits into my life, and I want to take something with food, and this is what I really want to take. But now I'm scared to do that. Maybe I should take this stuff that I don't think I can tolerate, that I don't think I can comply with."

And again, if it turns out that that data, in fact, suggest that he should stay away from those drugs, then it could be useful. But we do not have the proof.

MR. FROST (MODERATOR): How many of your clients are talking about genotype and phenotype these days? How important is resistance in the Houston community?

MS. LEONARD: When it first came out, with the novelty of it, we had people asking about it and so forth. But it has gone away. It is too overwhelming for people with everything else and just too confusing.

MR. FROST (MODERATOR): Did you think the lack of data around utility has contributed to that?

MS. LEONARD: We are talking about whether these drug regimens over the years will fail or whether they will extend somebody's lifetime. But I would like to bring up the fact that the toxicities over a lifetime, such as adult-onset diabetes and so forth, and some of the side effects of these drugs, are just as important an issue as whether they can sustain virologic response.

MR. FROST (MODERATOR): I think that is fair.

MS. PINSKY: Yes, I had a comment and two questions. I am somewhat distressed to hear the rejection of the idea of guidelines, not those specific guidelines, perhaps, but guidelines in general because I think then you always have a patient in a position of having to trust the doctor's judgment, whatever individual doctor he or she is seeing. I think that is a problem. I would be interested in knowing whether the other people on the panel who suggested using two-drug combination therapy also think that the recommendations were written the way they were only for sort of economic/political reasons. And if not, why they disagreed with the guidelines. Also, if they start people at a higher level of viral load and a lower level of CD4 cells, they still must have a number in mind. What are those numbers?

MR. FROST (MODERATOR): Dr. Dobkin, why don't you tackle that?

DR. DOBKIN: Let me just point something out beforehand. There were two documents produced at the same time. The other one, which is not called guidelines, I believe is called "Principles of Antiretroviral Therapy." I think this document is extremely useful because it summarizes a great deal of data in a concise form, most of which is not in textbooks, and a lot of which is not even in journal articles.

I have found it to be an extremely useful document for education. A lot of our house staff, 2 or 3 years out of medical school, do not know about any of the issues that we are talking about this morning. So I think there are guidelines and there are guidelines.

As far as the specific question is concerned, I think a knowledgeable user, and this should include a patient, looking at those guidelines has to realize what the limitations are of clinical trials, what a consensus means, and that it is not etched in stone by any means-that this is not a cookbook or a prescription that can be applied in robotlike fashion. 
MR. FROST (MODERATOR): Dr. El-Sadr? DR. EL-SADR: Yes, I actually support the guidelines, having been involved in developing some of them. Usually in guidelines, however, you have at least an acknowledgement of the level of certainty for each of the recommendations. And I think what worries me about these guidelines is that they are written without any indication of what each statement is based on. Is it simply expert opinion or is it based on a clinical trial? Is it based on observational studies? So, the reader really has no way of judging the strength of the evidence.

DR. COHEN: What also upsets me about the guidelines is that they are a bit glib about plan B. In other words, what they say is give plan A.

DR. SAAG: Let me sort of qualify my earlier comments. Is there a need for guidelines? Yes. Are they helpful? Yes. But I think we have to accept them for what they are. They are not dictums. They are guidelines. They are sort of road maps that you can follow, or you might not. And all of them say individualization of therapy.

What I was trying to say is that when we think about the impact of the guidelines on different target audiences, how they play is very different. So when you pitch guidelines to experienced "treaters," they are taken in the right spirit, I think. And there is a lot of comfort among experienced treaters to do what they need to do without feeling overly guilty.

And for the people that are inexperienced treaters, then the algorithm situation kicks in, and people start following it blindly, and getting patients into trouble because they do not have the depth of understanding of the principles that Dr. Dobkin was referring to.

So, I think they are helpful. I am not saying that they do not have a place. I am just saying that we should not put so much stock in them as if they are dictums. They are simply what they are-guidelines.

DR. HOLODNIY: I just want to give an anecdote in an entirely different area, which just happened to me. We were called to see a patient with infective endocarditis. The house staff working up the patient looked at the guidelines published in JAMA earlier this year regarding what constitutes infective endocarditis, and there are major and there are minor criteria. They looked at that, and said, "This patient doesn't fit the criteria of infective endocarditis." So they inadequately treated the patient in terms of duration.

The follow-up to the story is the patient, in fact, had infective endocarditis, and had to go for valve replacement. It was confirmed on histopathologic grounds when the valve was taken out.

So, again, the subtleties of it are important. And guidelines are useful as a framework. But there is a danger in adhering to those guidelines for whatever it is, if it is prostatic hypertrophy or it is infective endocarditis or whatever; if you take those guidelines too concretely, then patients will get into trouble. 